\title{
Cyclic Voltammetric and Electrochemical Simulation Studies on the Electro-Oxidation of Catechol in the Presence of 4, 4-bipyridine
}

\author{
Tekalign Kasa ${ }^{1}$, Theodros Solomon ${ }^{2}$ \\ ${ }^{1}$ Department of Chemistry, School of Natural Science, Madda Walabu University, Bale-Robe, Ethiopia \\ ${ }^{2}$ Department of Chemistry, School of Natural Science, Addis Ababa University, Addis Ababa, Ethiopia
}

Email address:

tekekasa@yahoo.com (T. Kasa)

\section{To cite this article:}

Tekalign Kasa, Theodros Solomon. Cyclic Voltammetric and Electrochemical Simulation Studies on the Electro-Oxidation of Catechol in the Presence of 4, 4-bipyridine. American Journal of Physical Chemistry. Vol. 5, No. 3, 2016, pp. 45-55. doi: 10.11648/j.ajpc.20160503.11

Received: February 21, 2016; Accepted: March 9, 2016; Published: April 16, 2016

\begin{abstract}
The studies were made using cyclic voltammetry on a glassy carbon electrode in aqueous solution containing phosphate buffer solution as supporting electrolyte. The purpose of the investigation was to carry out a quantitative detailed study of the electrochemical oxidation of catechol in the presence of 4, 4-bipyridine in aqueous solution. The electrooxidation of catechol produces a very reactive intermediate, $o$-benzoquinone, which subsequently reacts with 4, 4-bipyridine in 1, 4Michael addition reaction to form the corresponding catechol derivative product. The kinetic data were extracted from cyclic voltammograms with the help of digital simulation. The results of the study show that catechol is oxidized in aqueous phosphate buffer solution to a very reactive intermediate $o$-benzoquinone.
\end{abstract}

Keywords: Cyclic Voltammetry, EC Mechanism, Catechol, Benzoquinone, 4, 4-bipyridine

\section{Introduction}

Electrochemistry provides very interesting and versatile means for the study of chemical reactions. The majority of organic electrode reactions are characterized by the generation of a reactive intermediate at the electrode by electron transfer and subsequent reactions typical for that species. The main goal of the electrochemical studies is the elucidation of the sequence of electron transfer and chemical reactions that occur near the electrode surface and its applications to electro-synthesis of organic compounds. Among the organic compounds, catechol can be easily oxidized to the corresponding reactive o-benzoquinone mainly due to its low oxidation potential [1]. Catechol has the molecular formula of $\mathrm{C}_{6} \mathrm{H}_{6} \mathrm{O}_{2}$ and structure which is shown in the scheme 1 below.

Catechol is well known in biological systems often as a reactive center of electron transfer in the structure of many natural compounds and biologically reactive molecules capable of exhibiting both anti- and pro-oxidant behavior [2]. Catechol has a great importance in both biological and environmental analysis because of its excellent electrochemical activity and it can be used for the characterization of different analytical methods. It is used in a variety of applications including photography, dying, agrochemicals, rubber, plastic production antiseptic, dyestuffs, electroplating, specialty inks, antioxidants and light stabilizers, in organic synthesis, pharmaceutical industry, antibiotics, and flavor compounds such as vanillin, precursors are essential; they are the starting material for the production of the desired compound [1, 3-6].

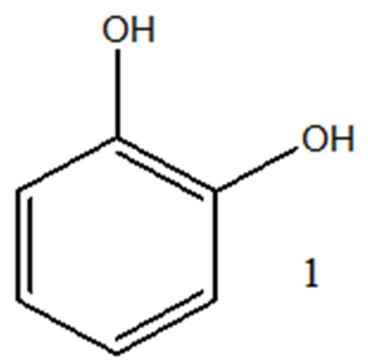

Catechol

Scheme 1. Structure of catechol. 
The electrochemical oxidation of catechol in aqueous solutions and in the presence of nuchleophiles shows that catechol undergoes 1, 4-Michael addition reactions according to the so-called EC mechanism with the consumption of 2 electrons per molecule of catechol, and a conversion to catechol derivatives [7]. The purpose of the investigation was to carry out a quantitative detailed study of the electrochemical oxidation of catechol in the presence of 4, 4bipyridine in aqueous solution.

\section{Experimental Parts}

\subsection{Chemicals}

The chemicals used were catechol (BDH Poole, England), 4, 4-bipyridine (Aldrich-chemie, Germany), $\mathrm{HCl}$ (RiedeldeHaen, Germany), $\mathrm{NaOH}$ (BDH Poole, England), sodium dihydrogen phosphate $\left(\mathrm{NaH}_{2} \mathrm{PO}_{4} \cdot 2 \mathrm{H}_{2} \mathrm{O}\right.$, Riedel-deHaen, Germany) and disodium hydrogen phosphate $\left(\mathrm{Na}_{2} \mathrm{HPO}_{4} \cdot 2 \mathrm{H}_{2} \mathrm{O}\right.$, Techno Pharmchem, India).

\subsection{Instrumentation}

The cyclic voltammetry apparatus used was BAS 100A electrochemical analyzer [Bio-analytical systems (BAS), USA], coupled to a Dell computer (Pentium 4). A JENWAY $3510 \mathrm{pH}$ Meter (Barloworld Scientific Ltd, Dunmow, Essex, U.K.) and Electronic Balance (Model: LA 204) were used. The three electrodes used in the voltammetry experiments were the glassy carbon electrode $(3 \mathrm{~mm}$ diameter) as working electrode, platinum wire as an auxiliary electrode and $\mathrm{Ag} / \mathrm{AgCl}(3 \mathrm{MKCl})$ as reference electrode, all from BAS. The working electrode (glassy carbon electrode) (GCE) was polished in each set of experiments with aluminum oxide powder $(0.3 \mu \mathrm{m})$ on a polishing cloth and followed by distilled water and were carried out at room temperature.

\subsection{Electrochemical Digital Simulation}

Digital simulation is a useful method in evaluation of complicated electrode reactions and used to visualize and verify electrochemical mechanisms and also used to determine the normalized current-over voltage curves for reversible as well as for quasi reversible reactions [8, 9]. By the development of simulation software cyclic voltammetry has become a very powerful technique [10]. The experimental parameters entered for digital simulation consisted of the following; $E_{\text {start }}=-0.2 \mathrm{~V}, E_{\text {switch }}=0.8 \mathrm{~V}$ and $\mathrm{T}=298 \mathrm{~K}$. The concentration of catechol and 4, 4-bipyridine were $1 \mathrm{mM}$. The transfer coefficient $(\alpha)$ was assumed to be 0.5 . The homogeneous rate constant $\left(k_{f}\right)$ of the chemical reaction of o-benzoquinone with 4, 4-bipyridine was estimated based on an EC mechanism by fitting the simulation data with experimental cyclic voltammogram data at various scan rates and $\mathrm{pHs}$, while the heterogeneous rate constant $\left(k^{o}\right)$ for the electrochemical oxidation of catechol to o-benzoquinone was estimated based on an E- mechanism of the simulation [11].The best simulation fits were obtained for the $\mathrm{E}_{\mathrm{r}} \mathrm{C}_{\mathrm{i}}$ mechanism.

\section{Result and Discussion}

\subsection{Cyclic Voltammetry of Catechol}

The number of electrons and protons involved in the oxidation of catechol can be determined from the separation peak potentials and from plots of $E^{o^{\prime}}$ vs $\mathrm{pH}$ and $E_{p a}$ vs $\mathrm{pH}$ respectively. The formal potential $\left(E^{o}\right)$, which is approximated by the midpoint potential $\left(E_{\text {mid }}\right)$ between the anodic and cathodic peaks is given by;

$$
E^{o \prime}=E_{p H_{o}}^{o}-\left(\frac{2.303 m R T}{n F}\right) p H
$$

Where $E_{\mathrm{pH} 0}^{o}$ is the formal potential at $\mathrm{pH}_{0}$, and $R, T$, and $F$ have their usual meanings and $n$ and $m$ are number of electron and proton respectively. The values of $E^{o}$, evaluated from the midpoint potential between the anodic and cathodic peaks, $\left(E_{\text {mid }}\right)$.

Both $E^{o}$ and $E_{p a}$ were shifted to negative potentials with the slope of $62 \mathrm{mV} / \mathrm{pH}$ with the correlation function $\mathrm{R}(\mathrm{R}=$ $0.999601)$ and $63.3 \mathrm{mV} / \mathrm{pH}$ with the correlation function $\mathrm{R}$ $(\mathrm{R}=-0.999004)$ respectively. In all cases, the slopes are in good agreement with the theoretical slope $(2.303 m R T / \mathrm{n} F)$ of $59 \mathrm{mV} / \mathrm{pH}$ with $m \approx 2$ and $n=2$, where $n$ and $m$ are number of electron and proton respectively [12].

\subsection{Effect of $\mathrm{PH}$}

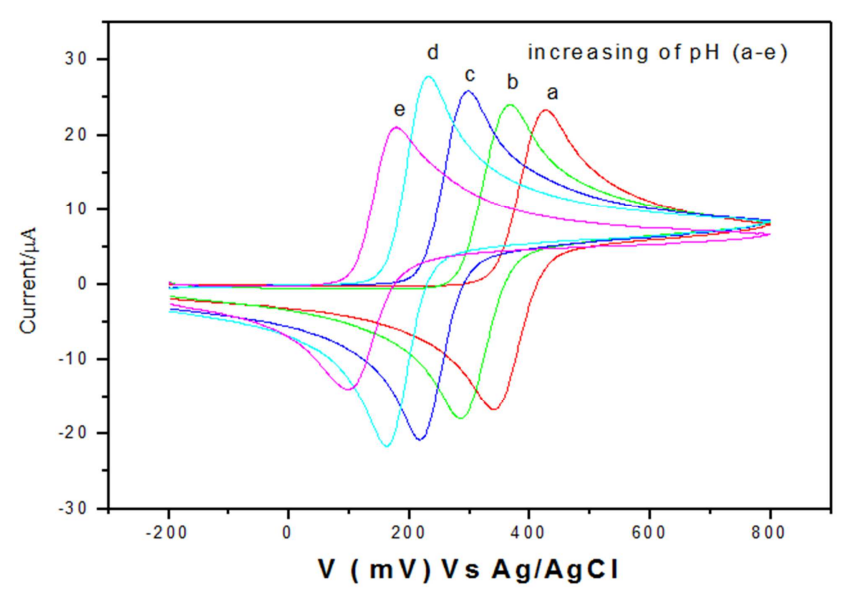

Figure 1. Typical cyclic voltammograms for $1 \mathrm{mM}$ catechol at various $\mathrm{pHs}$ a) 4, b) 5, c) 6, d) 7 and e) 8 at a scan rate of $50 \mathrm{mV} / \mathrm{s}$.

On increasing the $\mathrm{pH}$ of supporting electrolyte both the anodic and cathodic peak potentials shifted towards more negative potential [13] as shown in the Figure 1. This is expected because of the participation of proton in the oxidation reactions and these shifts of potential indicate that the electron transfer process from catechol to o-benzoquinone occurs at glassy carbon electrode easily at higher $\mathrm{pH}$ than at lower $\mathrm{pH}$. The electrooxidation of catechol was found to be $\mathrm{pH}$ dependent. In acidic and neutral media catechol showed a well developed quasi-reversible wave as indicated in Figure 1 
below. Under these conditions, a peak current ratio $\left|i_{p c} / i_{p a}\right|$ of nearly unity can be considered as a criterion for the stability of o-benzoquinone produced at the surface of the electrode under the experimental conditions. In basic solutions, the peak current ratio is less than unity and decreases with increasing $\mathrm{pH}$. These shifts can be associated to the coupling of the anionic or dianionic forms of catechol with obenzoquinones (dimerization reactions) [2].

Figure 2 below shows that the anodic peak current increases as the $\mathrm{pH}$ increases and reaches the highest peak at $(\mathrm{pH}=7)$ and then decreases. The highest anodic peak current (at $\mathrm{pH}=7$ ) was taken as the optimum $\mathrm{pH}$ for the electrooxidation of catechol.

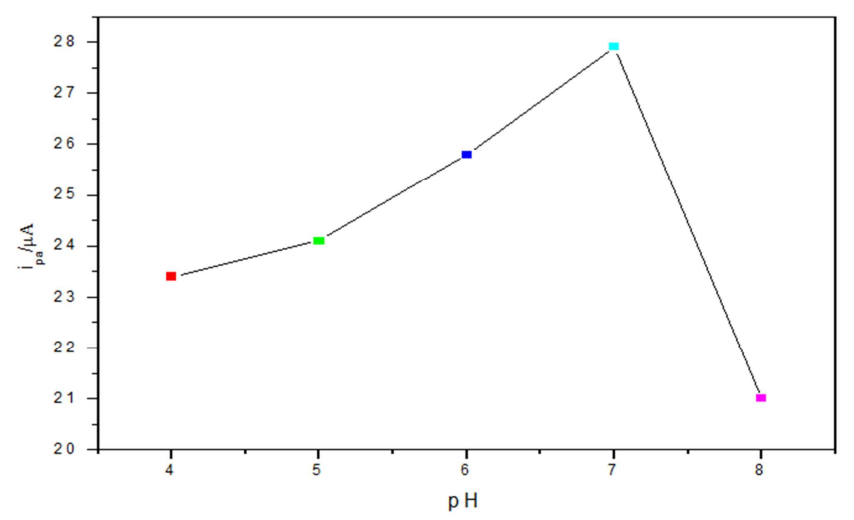

Figure 2. $i_{p a}$ as a function of $p H$ for $1 \mathrm{mM}$ catechol at a scan rate of 50 $\mathrm{mV} / \mathrm{s}$.

\subsection{Effect of Scan Rate}

As shown in Figure 3, when the scan rate increases, both the anodic and cathodic peaks increase; the anodic peak shifts towards less positive potentials while the cathodic peak shifts

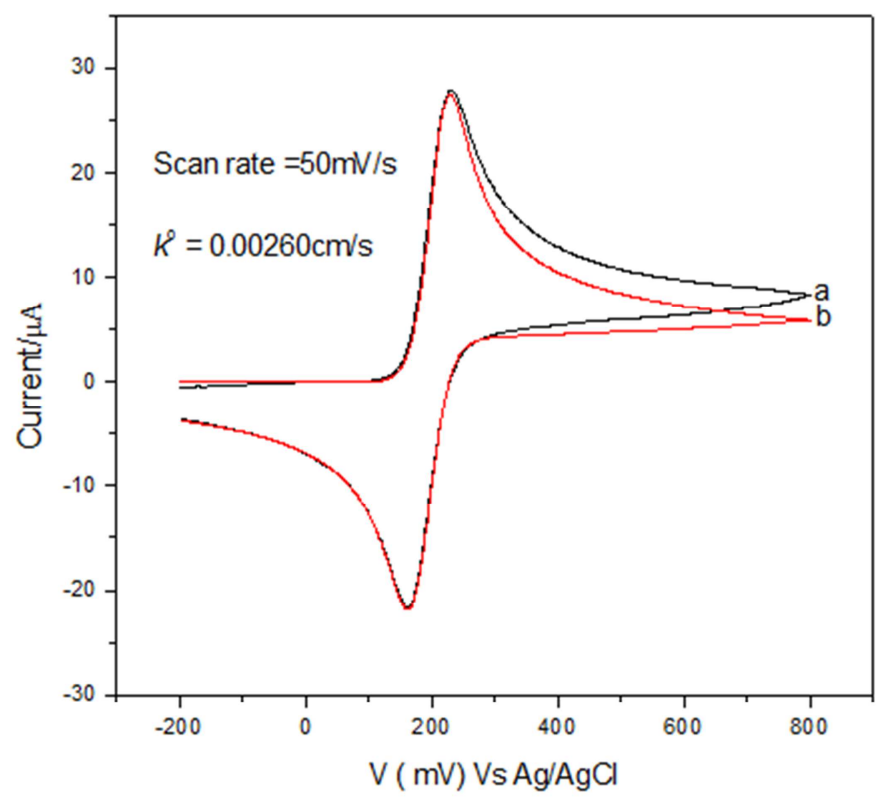

towards more positive potentials. Overall, the current ratios are almost unity and the peak separation between the anodic and cathodic peak potential at scan rate of $50 \mathrm{mV} / \mathrm{s}$ is 69 $\mathrm{mV} / \mathrm{n}$ which is greater than $59 \mathrm{mV} / \mathrm{n}$ and it is one of the indications that the system is a quasi-reversible process.

A peak current ratio $\left|i_{p c} / i_{p a}\right|$ of nearly unity, particularly during the repetitive recycling of potential, can be considered as criteria for the stability of o-benzoquinone produced at the surface of electrode under the experimental conditions. It means that any hydroxylation or dimerization reactions are very slow which was observed in the time-scale of cyclic voltammetry $[2,14,15]$.

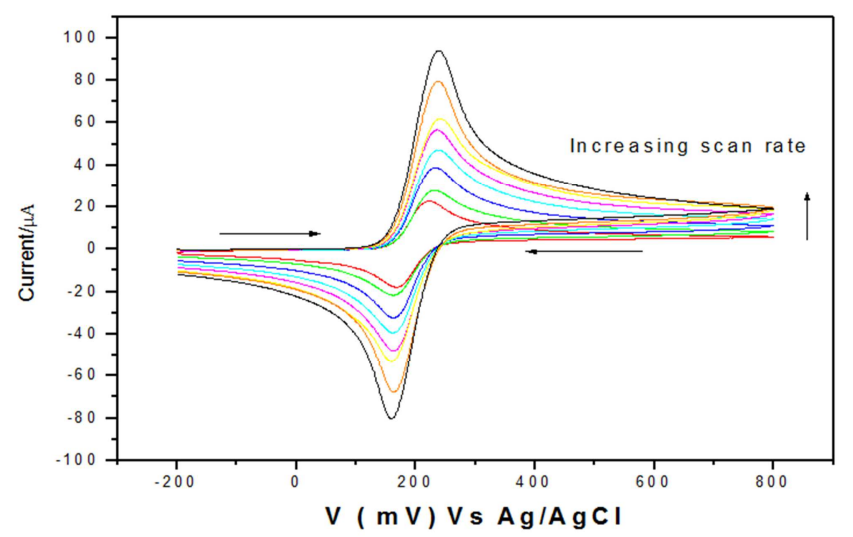

Figure 3. Cyclic voltammograms of $1 \mathrm{mM}$ catechol at scan rates of; 30, 50,100,150, 200,250, 300 and 400mV/s at phosphate buffer solution of $\mathrm{pH}=7$.

\section{DETERMINATION OF HETEROGENEOUS RATE CONSTANT $\left(k^{\circ}\right)$ AT VARIOUS SCAN RATES}

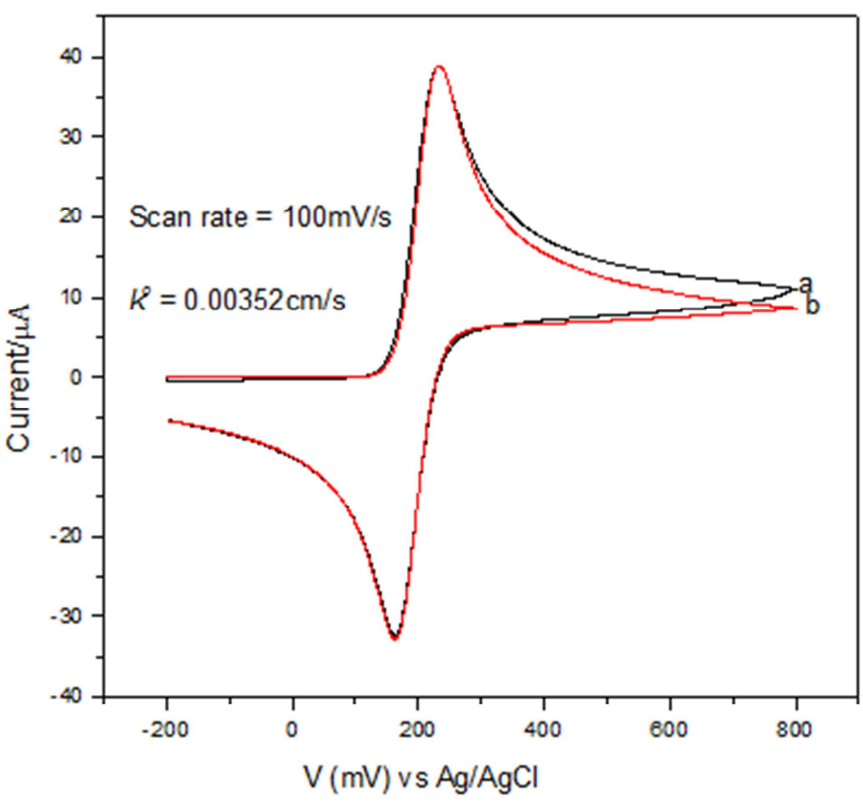



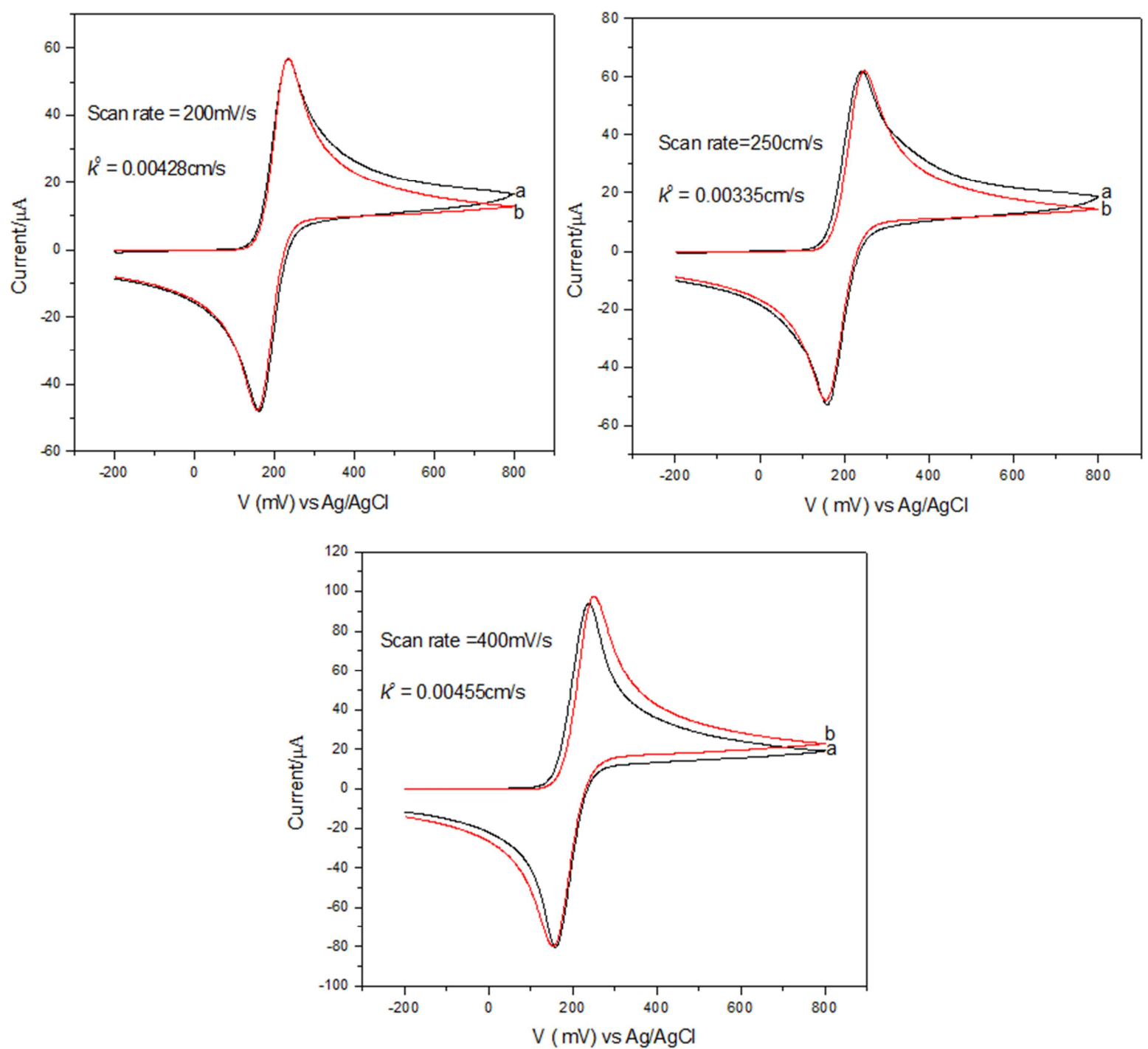

Figure 4. Typical cyclic voltammograms of $1 \mathrm{mM}$ catechol at various scan rates at pHs 7. (a) Experimental; (b) simulated.

\section{DETERMINATION OF HETEROGENEOUS RATE CONSTANT $\left(k^{\circ}\right)$ AT VARIOUS pHs}
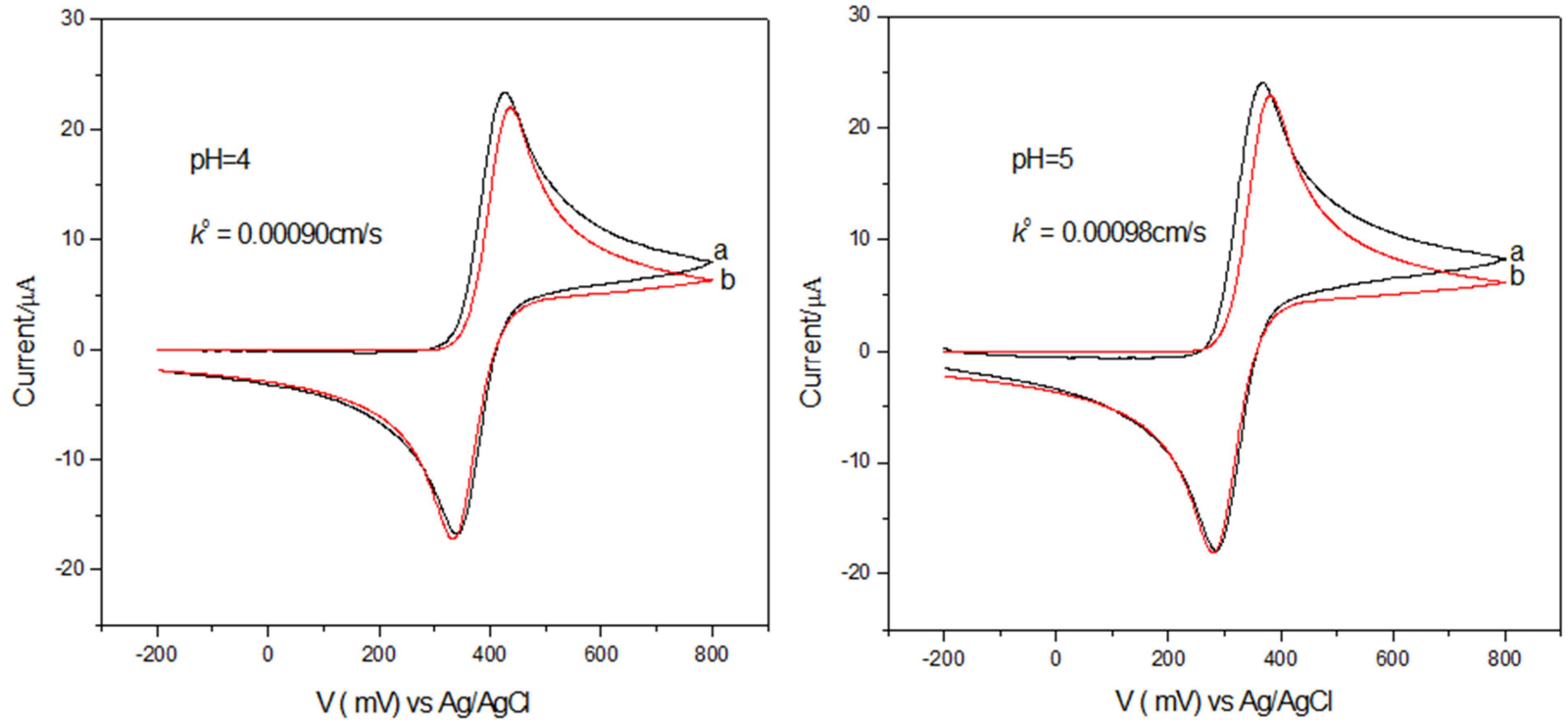

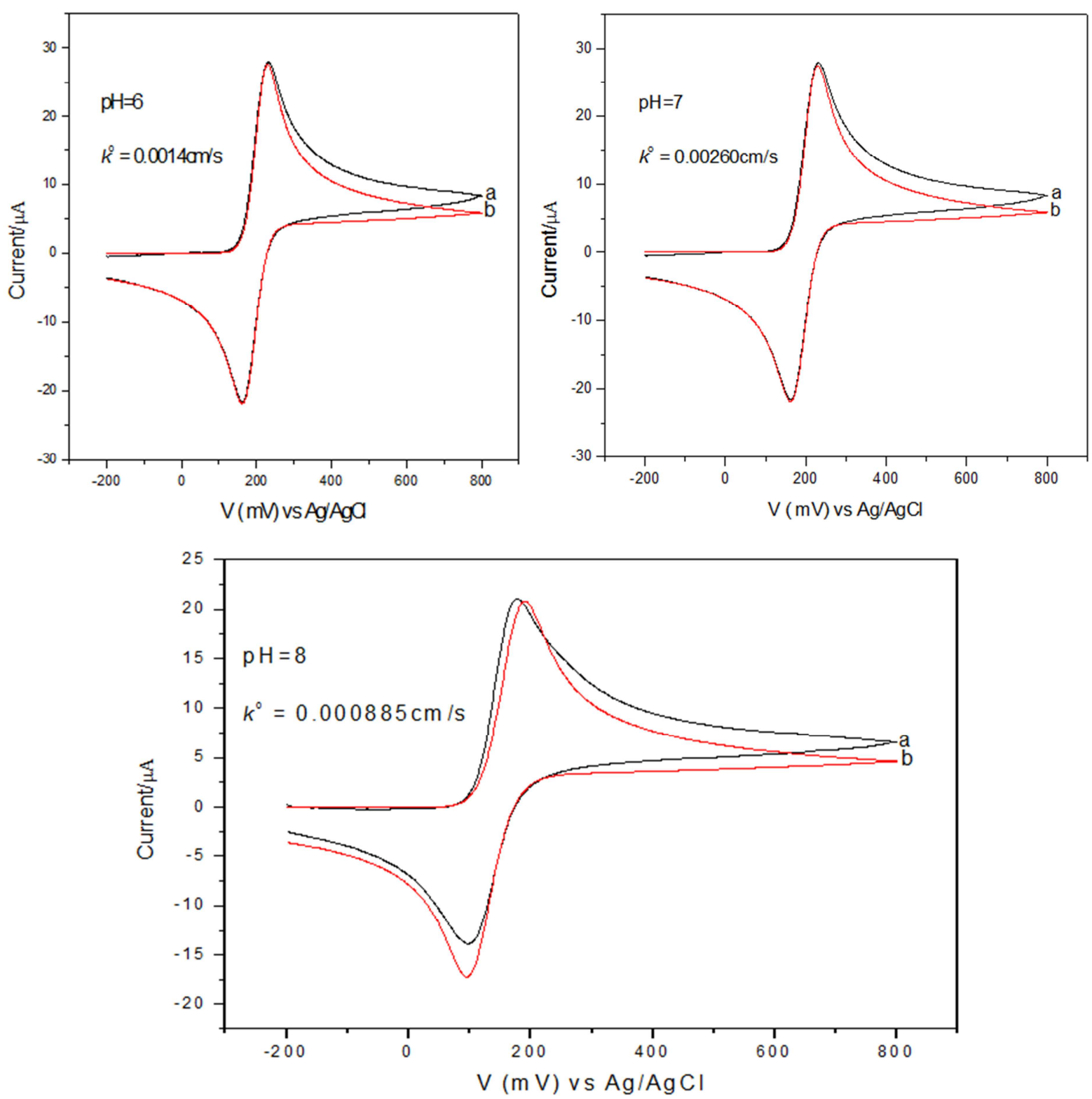

Figure 5. Typical cyclic voltammograms of $1 \mathrm{mM}$ catechol at various $\mathrm{pHs}$ at a scan rate of $50 \mathrm{mV} / \mathrm{s}$. (a) experimental; (b) simulated.

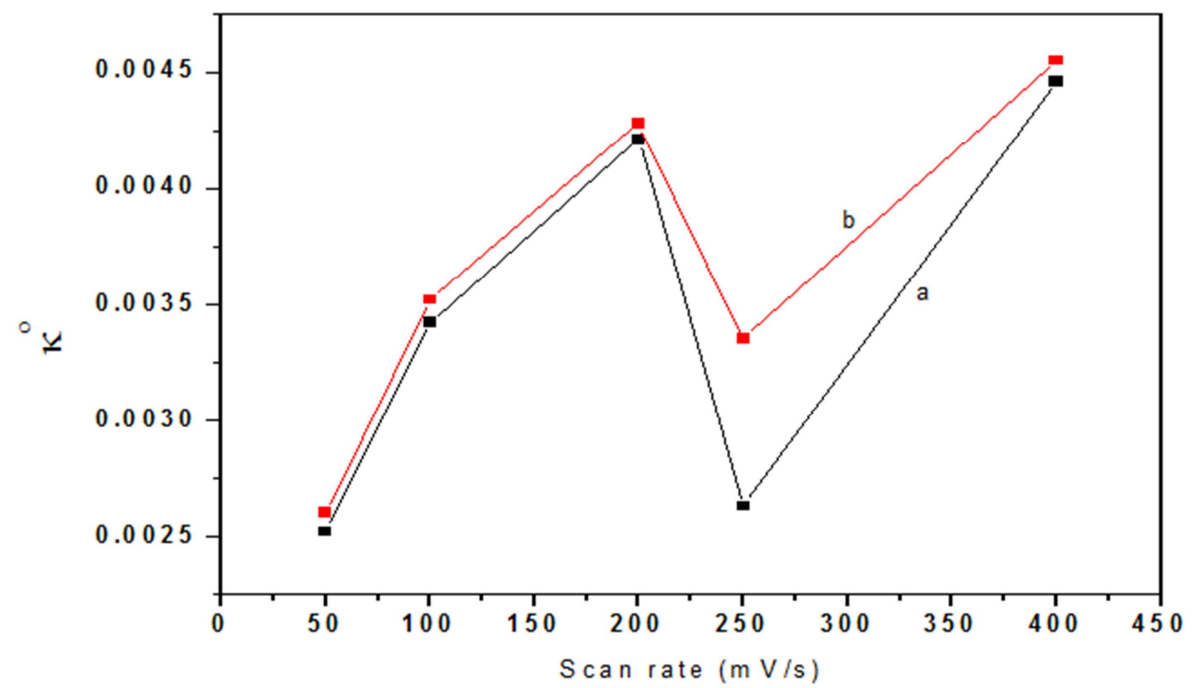

Figure 6. Variation of experimental (a) and simulated (b) heterogeneous rate constant $\left(k^{\circ}\right)$ as the function scan rate at pH 7. 


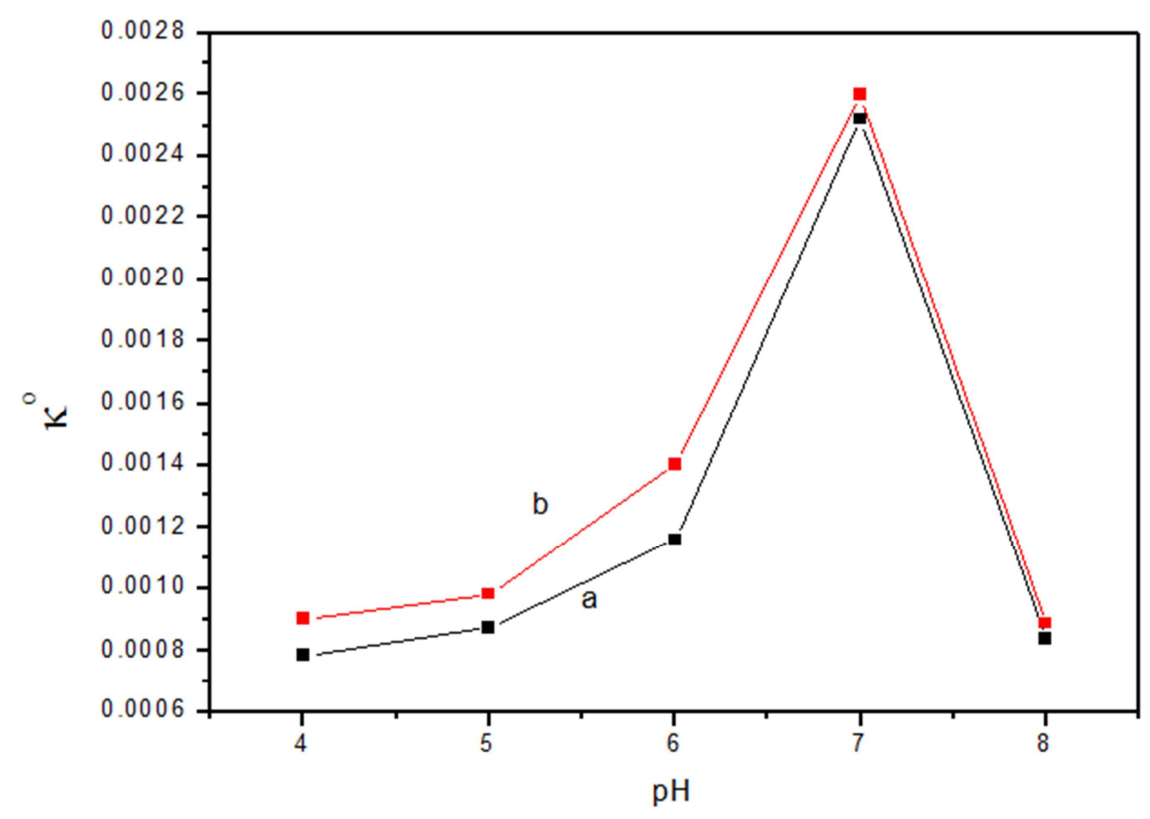

Figure 7. Variation of experimental (a) and simulated (b) heterogeneous rate constant $\left(k^{\circ}\right)$ as the function $\mathrm{pH}$ at $50 \mathrm{mV} / \mathrm{s}$.

As can be seen from the data in Figure 6 and 7, there is a good correlation between the heterogeneous rate constant $\left(k^{\circ}\right)$ calculated using the Nicholson and Shain method and the heterogeneous rate constant $\left(k^{o}\right)$ obtained using digital simulation at various scan rates and $\mathrm{pHs}$.

\subsection{Cyclic Voltammetry of Catechol in the Presence of 4, 4-Bipyridine}

The cyclic voltammogram of catechol in aqueous solution of $0.2 \mathrm{M}$ phosphate buffer at $\mathrm{pH}=7$ shows one anodic and the corresponding cathodic peak. As $1 \mathrm{mM} 4$, 4-bipyridine is added to $1 \mathrm{mM}$ catechol, the height of the cathodic and anodic peak currents decreased, while the potential of anodic peak to some extent shifted towards a less positive potential as shown in Figure 8 below. The shift of the anodic peak potential in the presence of 4, 4-bipyridine may due to the coupled homogeneous chemical reaction product formed at the surface of the electrode.

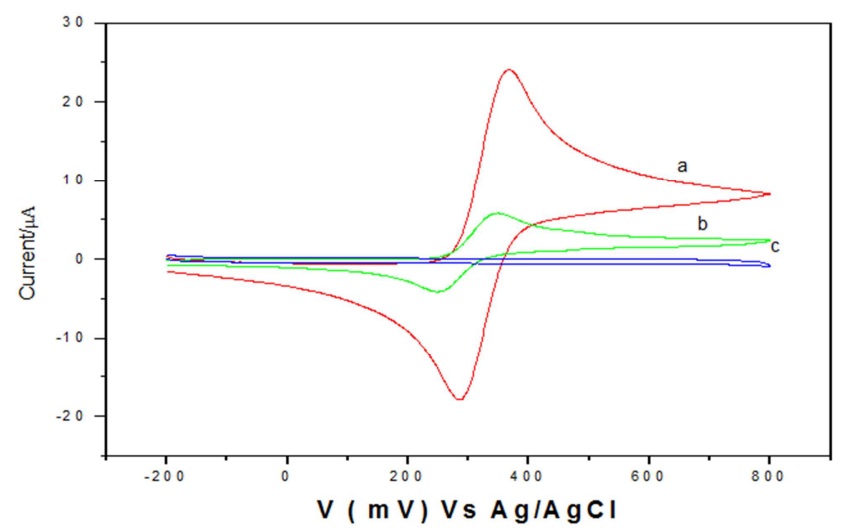

Figure 8. Cyclic voltammograms of $1 \mathrm{mM}$ catechol in the absence (a) and in the presence of $1 \mathrm{mM} \mathrm{4,} \mathrm{4-bipyridine} \mathrm{(b),} \mathrm{and} \mathrm{that} \mathrm{of} \mathrm{a} 1 \mathrm{mM} \mathrm{4,} \mathrm{4-bipyridine}$ alone (c) at the glassy carbon electrode in $0.2 \mathrm{M}$ phosphate buffer at different $\mathrm{pH}$ at a scan rate of $50 \mathrm{mV} / \mathrm{s}$.

\subsection{Effect of $\mathrm{pH}$}

According to figure 9 the cyclic voltammogram of $1 \mathrm{mM}$ catechol in the presence of 4, 4-bipyridine shows that the anodic and cathodic peak potentials shifted towards less positive values as the $\mathrm{pH}$ increased. As shown in Figure 10 below also the peak current ratio $\left|i_{p c} / i_{p a}\right|$ of catechol in the presence of 4, 4-bipyridine increasedwith increasing $\mathrm{pH}$ until it reached a maximum at $\mathrm{pH} 6$ and then decreased after this pH.This can be related to protonation of the nucleophile 4, 4bipyridine at lower $\mathrm{pHs}$ and its deprotonation at higher $\mathrm{pHs}$. In other words, in acidic and neutral medium, the peak current ratio $\left|i_{p c} / i_{p a}\right|$ of nearly unity can be considered as criteria for the stability of o-benzoquinone produced at the surface of the electrode.

However, in basic solutions, the peak current ratio is less than unity and decreases with increasing $\mathrm{pH}$. These changes can be related to the coupling of the anionic or dianionic forms of catechols with $o$-quinones (dimerization reactions) $[16,17]$.

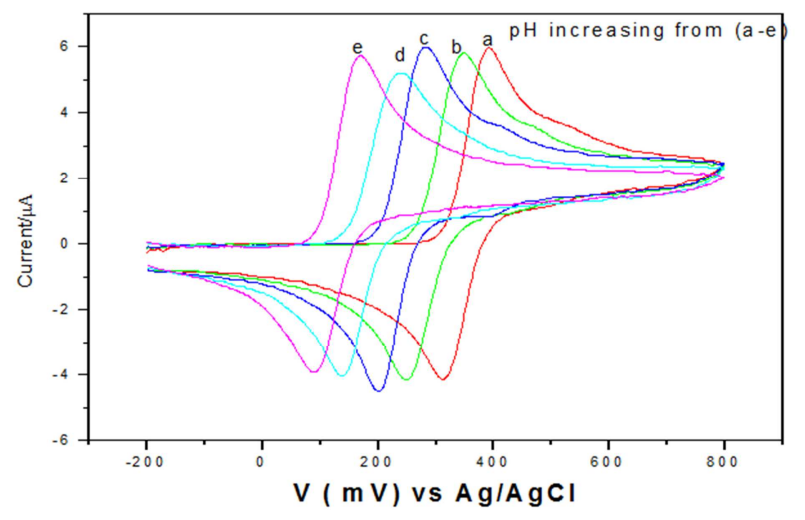

Figure 9. Cyclic voltammograms of catechol in the presence of 4, 4bipyridine at glassy carbon electrode at a scan rate of $50 \mathrm{mV} / \mathrm{s}$ and various pHs: a) 4, b) 5, c) 6, d) 7 and e) 8 . 


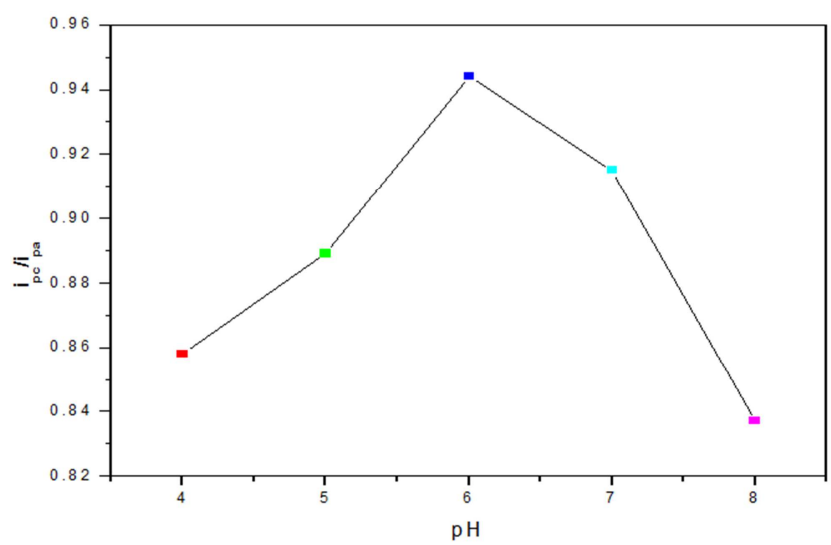

Figure 10. Current ratio $\left|i_{p c} / i_{p a}\right|$ versus $p H$ for $1 m M$ catechol in the presence of $1 \mathrm{mM}$ 4, 4-bipyridine.

Figure 11 below shows that the anodic peak current decreases as $\mathrm{pH}$ increases and attain its highest value at $(\mathrm{pH}=$ 6) and then slightly decreases with $\mathrm{pH}$. The highest anodic peak current occurred at $\mathrm{pH}=6$ and this is the optimum $\mathrm{pH}$ for electrooxidation of catechol in the presence of 4, 4-bipyridine.

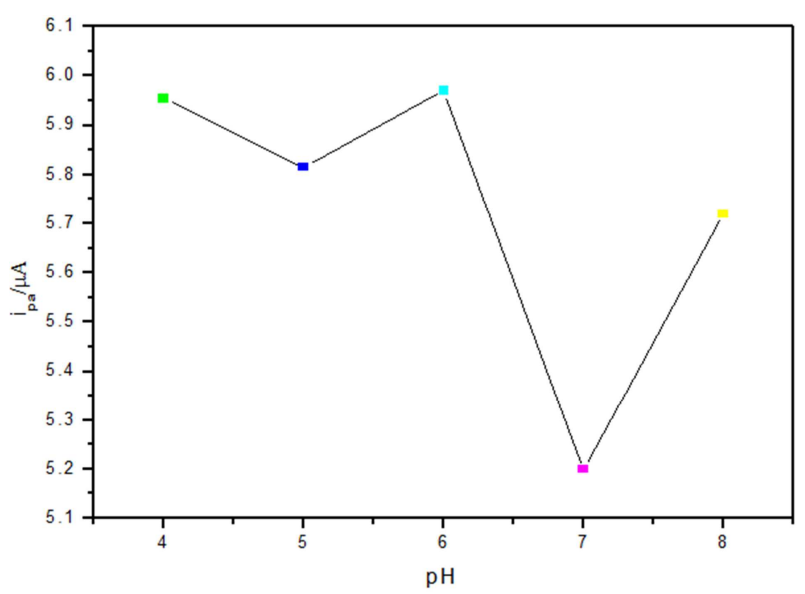

Figure 11. Anodic peak current $i_{p a}$ as a function of $\mathrm{pH}$ for catechol in the presence of 4, 4-bipyridine at a scan rate of $50 \mathrm{mV} / \mathrm{s}$.

\subsection{Effect of Scan Rate}

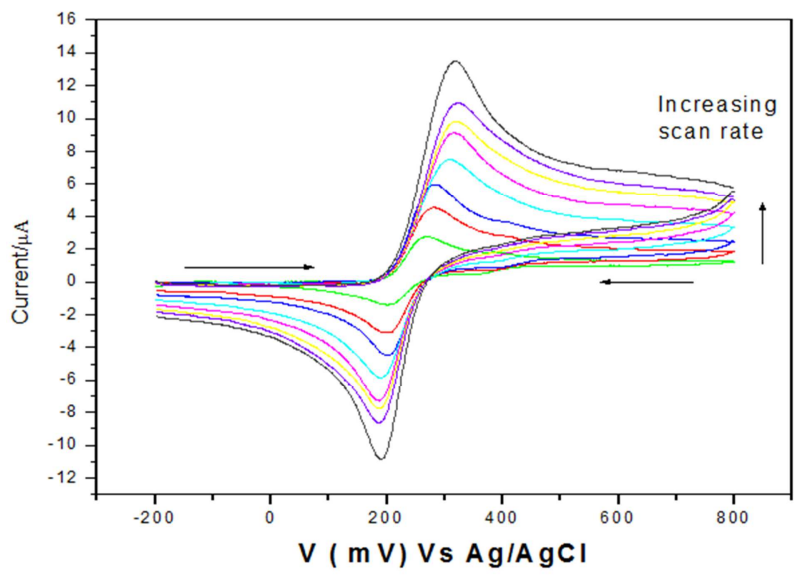

Figure 12. Cyclic voltammograms of $1 \mathrm{mM}$ catechol in the presence of 4, 4bipyridine at scan rates of(10-300) $\mathrm{mV} / \mathrm{s}$ at phosphate buffer solution of $p H=6$.
The effect of the scan rates $(10-400 \mathrm{mV} / \mathrm{s})$ on the electrooxidation of catechol in the presence of 4, 4-bipyridine was studied. Figure 12 show that both the magnitude of anodic and cathodic peak potentials increased with increasing scan rate. The peak current ratio $\left|i_{p c} / i_{p a}\right|$ increased as the scan rate increased and this indicates that a chemical reaction occurred between 4, 4-bipyridine and o-benzoquinone [18].

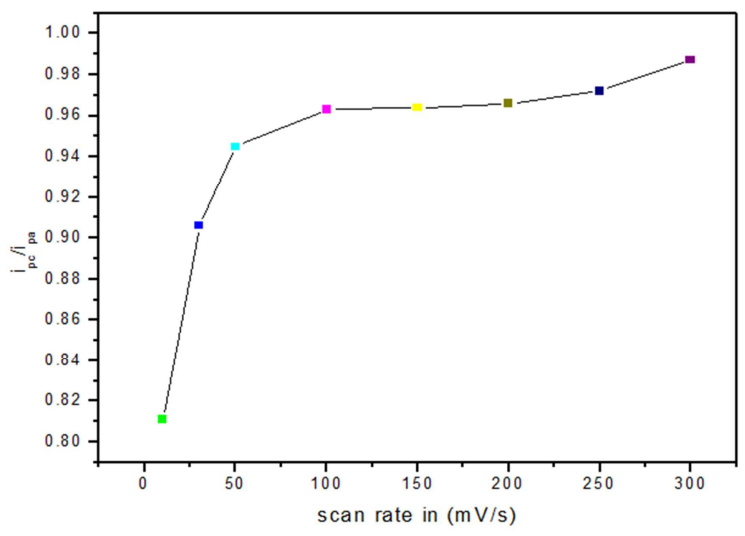

Figure 13. Current ratio $\left|i_{p d} / i_{p a}\right|$ as function of scan rate for $1 m M$ catechol in the presence of $1 \mathrm{mM} 4$, 4-bipyridine.

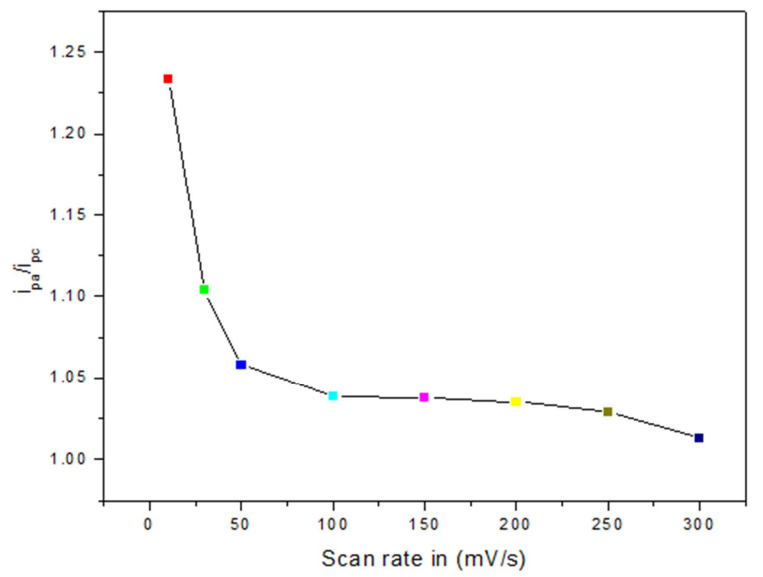

Figure 14. Current ratio $\left|i_{p a} / i_{p c}\right|$ versus scan rate for catechol in the presence of 4, 4-bipyridine.

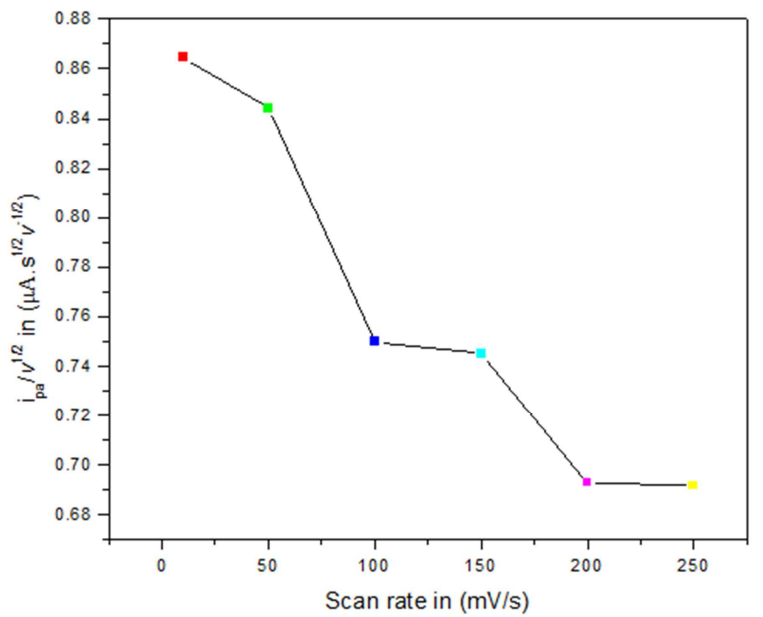

Figure 15. Current function $i_{p a} / v^{1 / 2}$ at different scan rate (v) for catechol in the presence of 4, 4-bipyridine at $\mathrm{pH}=6$. 
The cyclic voltammogram of catechol in the presence of the nucleophile at different scan rates shows an increasing of peak current ratio $\left|i_{p c} / i_{p a}\right|$, decreasing of $\left|i_{p a} / i_{p c}\right|$ and the decreasing of current function $i_{p a} / v^{1 / 2}$ with increasing scan rate. As shown in Figures 13, 14 and 15; it is a clear indication of coupled chemical reaction following an $\mathrm{E}_{\mathrm{r}} \mathrm{C}_{\mathrm{i}}$ mechanism [19] and also the reactivity of deprotonated 4, 4-bipyridine towards o-benzoquinone.

Determination of homogeneous rate constant $\left(k_{f}\right)$ by using electrochemical simulation method at various scan rates.

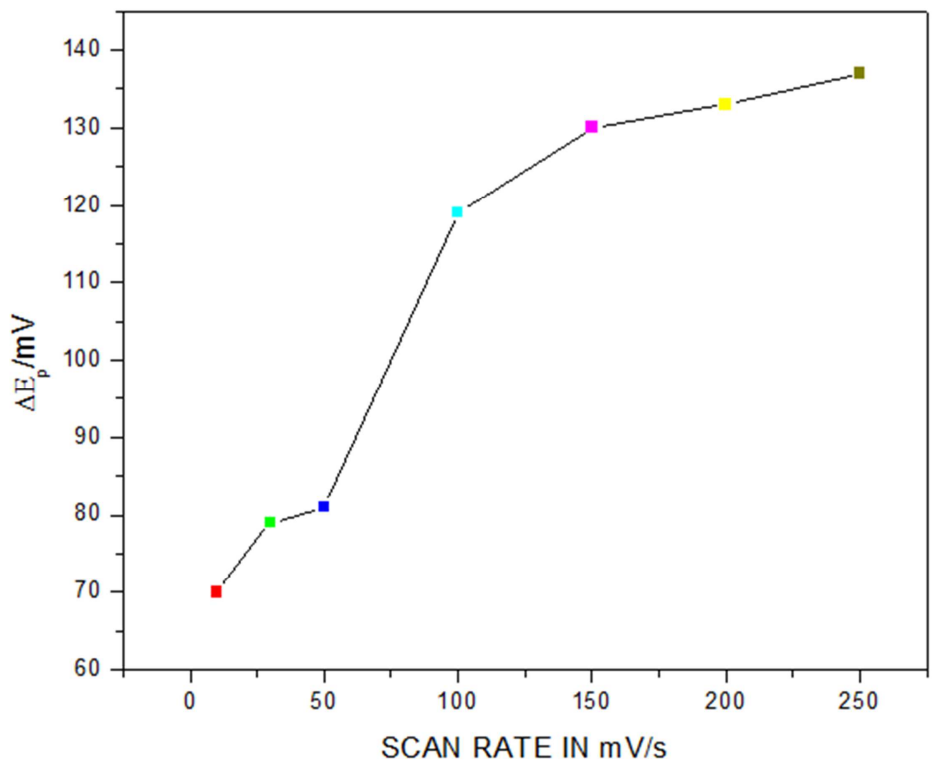

Figure 16. Separation of peak potentials $\left(\Delta E_{p}\right)$ as a function of scan rate (v) for $1 \mathrm{mM}$ catechol in the presence of $1 \mathrm{mM} 4$, 4-bipyridine at (pH=6).
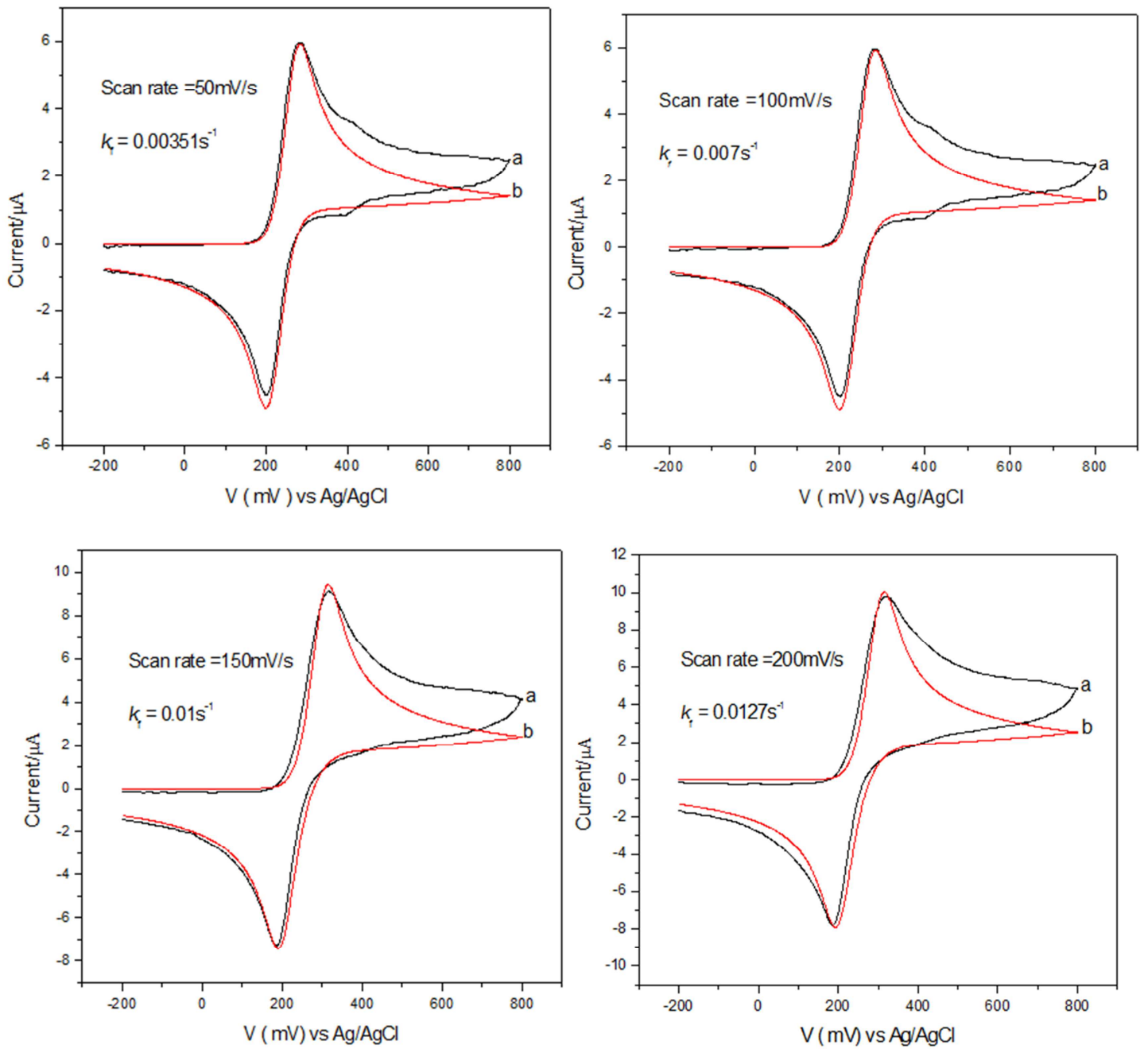

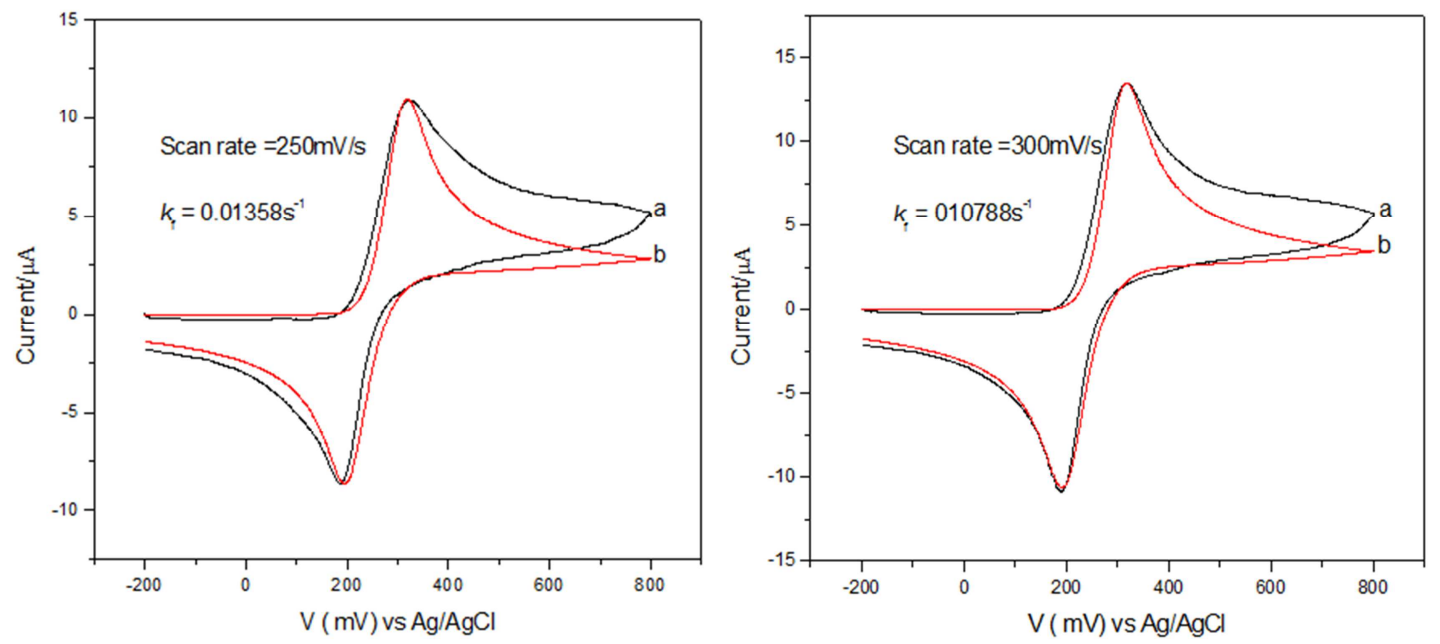

Figure 17. Cyclic voltammograms for $1 \mathrm{mM}$ catechol in the presence of 4, 4- bipyridine at $\mathrm{pH}=6$ at different scan rates. (a) Experimental; (b) simulated.

As shown in Figure 18 below the $k_{f}$ values from Nicholson's working curve were in good agreement with the $k_{f}$ values of the electrochemical simulation results.

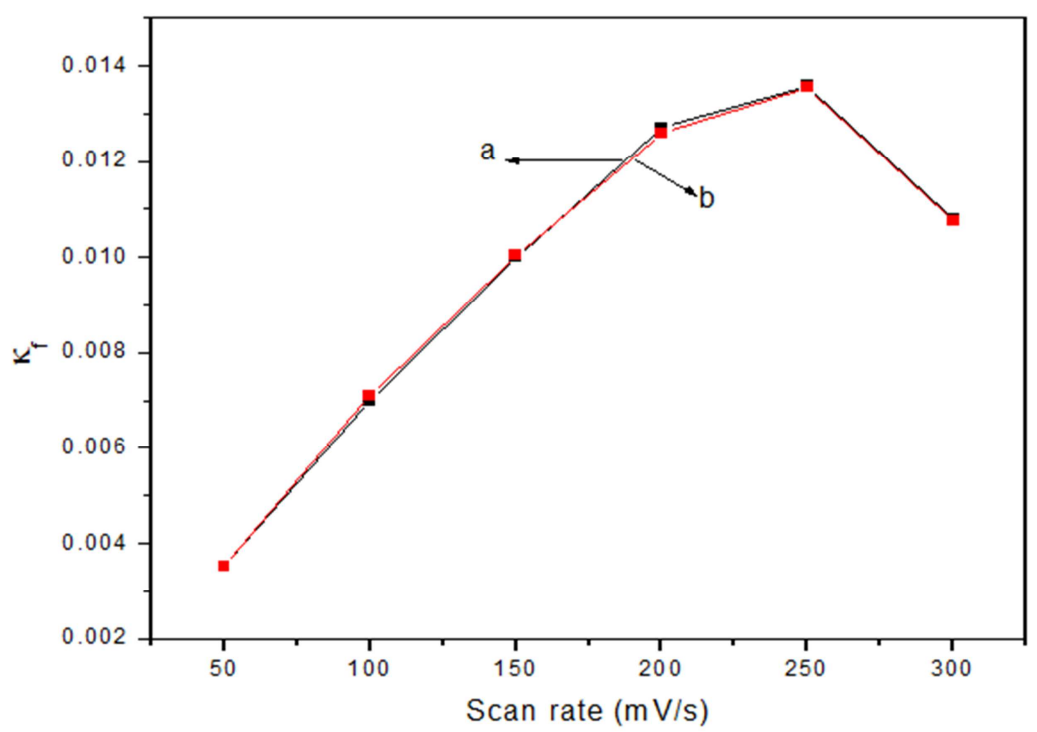

Figure 18. Variation of experimental (a) and simulated (b) homogeneous rate constant $\left(k_{f}\right)$ as a function scan rate at $p H$ of 6.

Determination of homogeneous rate constant $\left(k_{f}\right)$ by using electrochemical simulation method at various PHs
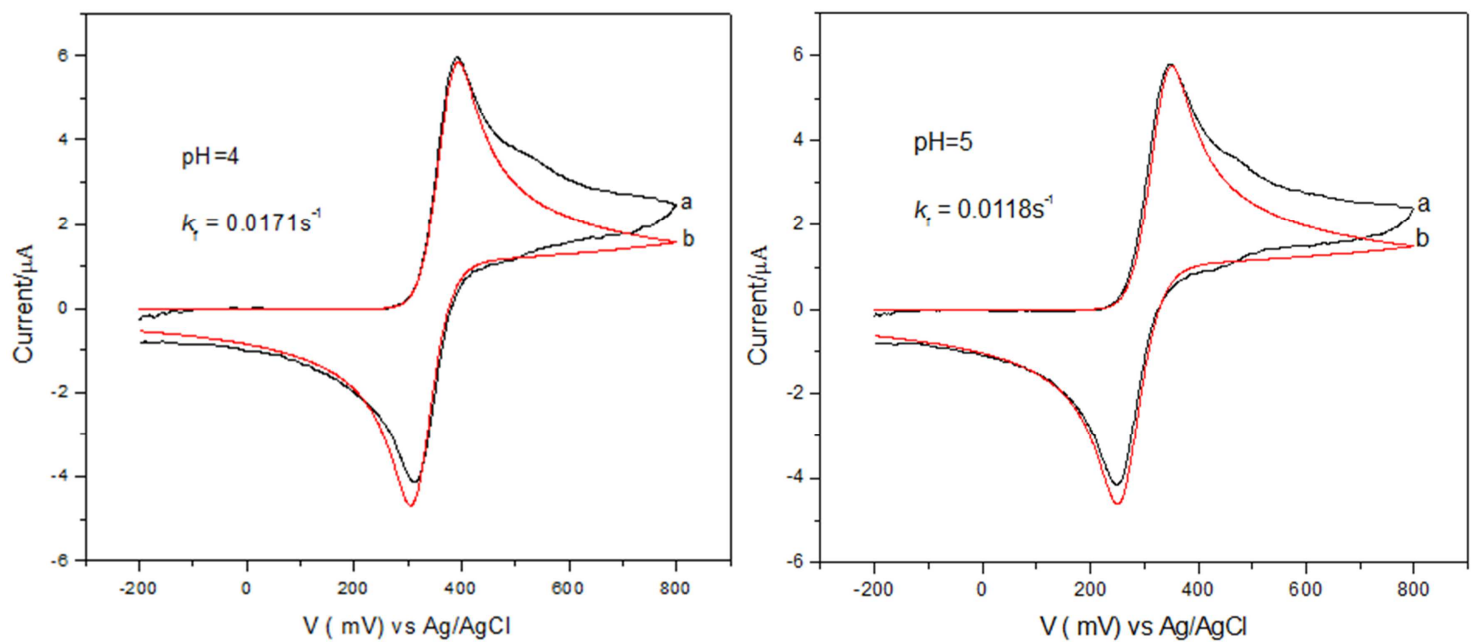

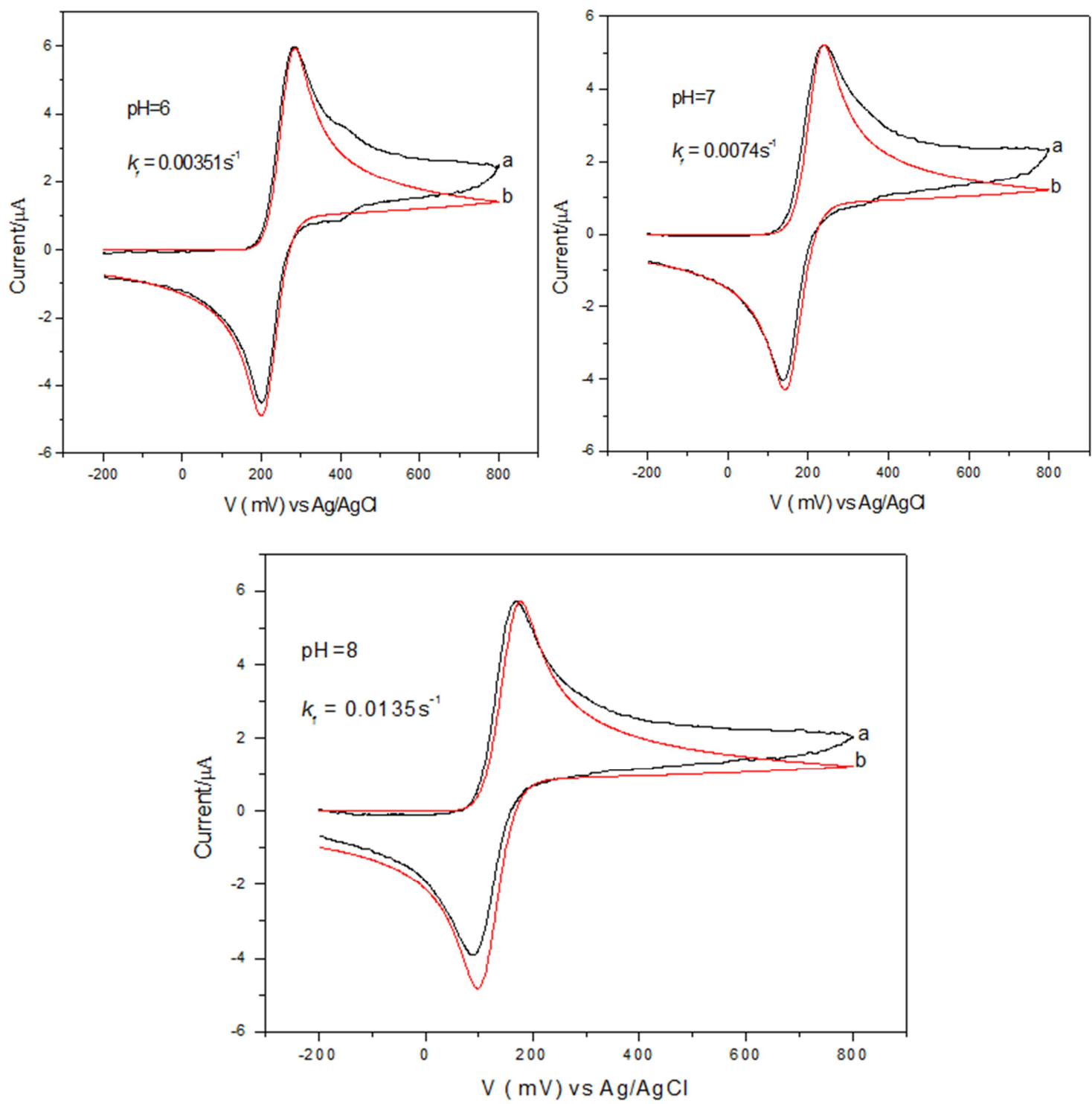

Figure 19. Typical cyclic voltammograms of $1 \mathrm{mM}$ catechol in the presence of $1 \mathrm{mM} 4,4$ bipyridine at various pHs at a scan rate of $50 \mathrm{mV} / \mathrm{s}$. (a) experimental; (b) simulated.

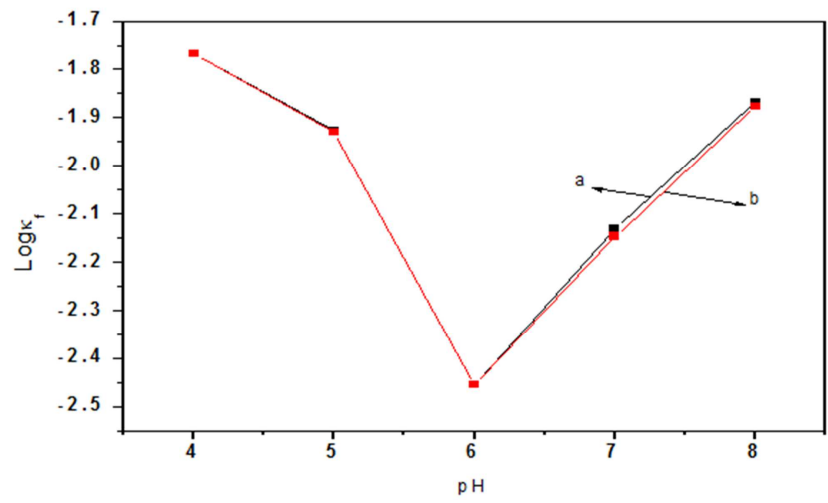

Figure 20. Calculated (a) and simulated (b) homogeneous rate constant $\left(k_{f}\right)$ as a function $\mathrm{pH}$ at $50 \mathrm{mV} / \mathrm{s}$.

As shown in the Figure 20 above the experimental values of $k_{f}$ at various pHs at the scan rate of $50 \mathrm{mV} / \mathrm{s}$ were in good agreement with the $k_{f}$ values of simulation values.

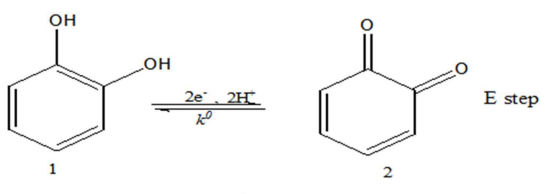<smiles>O=C1C=CC=CC1=O</smiles>

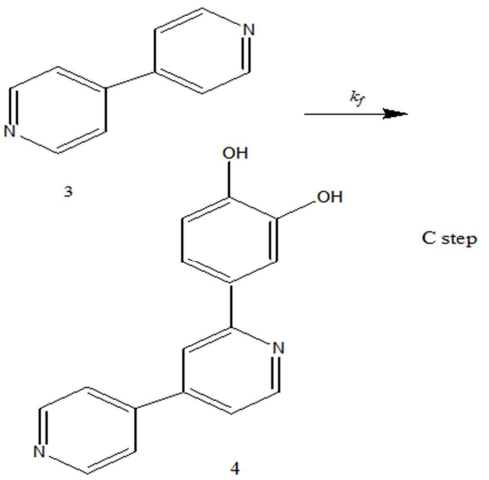

Scheme 2. Proposed mechanism for electrooxidation of catechol in the presence of 4, 4-bipyridine. 


\section{Conclusion}

The results of the study show that catechol is oxidized in aqueous phosphate buffer solution to a very reactive intermediate $o$-benzoquinone. The oxidation of catechol in the absence of 4, 4-bipyridine showed properties ofa quasireversible two-electron two-proton process, whereas, the oxidation of catechol in the presence of 4, 4-bipyridine follows an $\mathrm{E}_{\mathrm{r}} \mathrm{C}_{\mathrm{i}}$ mechanism with an irreversible chemical reaction. The o-benzoquinone is attacked in 1, 4-Michael addition reaction by 4, 4-bipyridine to form catechol derivative. The kinetic parameters for the electrooxidation of catechol in the absence and presence of 4, 4-bipyridine at different scan rates and $\mathrm{pHs}$ were studied using cyclic voltammetry and electrochemical digital simulation.

\section{References}

[1] Nematollahi, D., Rafiee, M., Fotouhi, L. 2009: Journal of Iranian Chemical Society, pp 448-476.

[2] Fotouhi, L., Khakpour, M., Nematollahi, D., Heravi, M., 2008: ARKIVOC; 2, pp 43-52.

[3] IARC, 1987: Monographs on the evaluation of carcinogenic risks to human, supplement, 7, 71, pp 433-451.

[4] Krab-Hüsken, L., 2002: Production of catechol; Microbiology and technology.

[5] Tao, Y., Fishman, A., William, E., Bentley, Thomas, 2004: Applied Environmental Microbiology, 70, pp 3814-3820.

[6] Malisova, B., 2010: Polymer Immobilization to Metal Oxide Substrate through Catechol Derivatives as Surface Anchors.
[7] Nematollahi, D., Alimoradi, M., Husain, W., 2004: Electroanalysis, 16, pp 1359-1365.

[8] Bolinger, W., 2000: The Deployment of Digital Simulation Tools to Verify Cyclic Voltammetry Experiments.

[9] Demortier, A., Jehoulet, C., 1990: Journal of Electro analytical Chemistry and Interface Electro-chemistry, 283, pp 15-33.

[10] Nematollahi, D., Mohammad, L., 2009: International Journal of Electro-chemical Science, 4, pp1583-1592.

[11] Petrovic, S., 2000: Chemical Educator, 5, pp 231-235.

[12] Afkhami, A., Nematollahi, D., Khalafi, L., Rafiee, M.., 2005: International Journal of Chemical Kinetics, 37, pp 17-24.

[13] Fotouhi, L., Tammari, E., Asadi, S., Heravi, M., 2009: International Journal of Chemical Kinetics, 41, 426-431.

[14] Nematollahi, D., Afkhami, A., Mosaed, F., Rafiee, M., 2004: Research of Chemical Intermediate, 30, pp 299-309.

[15] Fakhari, A.., Hosseiny, S., Davarani., Ahmar, H., Makarem, S., 2008: Journal of Applied Electro-chemistry, 38, pp 17431747.

[16] Fotouhi, L., Asadi, S., Tammari, E., Heravi, M.; Nematollahi, D., 2008: Journal of Iranian Chemical Society, 5, pp 712-717.

[17] Fotouhi, L., Behrozi, L.; Heravi, M.; Nematollahi, D., 2009: Phosphorus, Sulfur, and Silicon and Related Elements, 184, pp 2749-2757.

[18] Dowlati, B., Nematollahi, D., Othman, M., 2011: International Journal of Electro-chemical Science, 6, pp 57675778.

[19] Nematollahi, D., Ardakani, M.., Shekarlab, N., 2007: International Journal of Chemical Kinetics, 39, pp 605-613. 